\title{
Metodología y resultados previos en el estudio de fragmentos de fauna en morteros romanos
}

\author{
Methodology and previous results in the study of faunal \\ fragments in Roman mortars
}

\section{Pablo Guerra-García \\ Felipe Gómez-Moreno \\ César Manuel Heras-Martínez \\ Ana Bastita-Ramírez}

\section{Resumen}

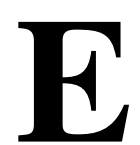

l yacimiento arqueo-antropológico de La Magdalena, en el término municipal de Alcalá de Henares (España), está compuesto por varias necrópolis de diferentes cronologías y por diversos complejos de producción de época Romana. Durante la intervención arqueológica, se documentaron diferentes estructuras de carácter industrial. Estas estructuras fueron edificadas con diferentes tipos de mortero de cal, desde los cimientos - opus caementicium - hasta la cubrición definitiva - opus signinum. Todas ellas siguen las mismas pautas de construcción romana, empleando, entre otras, cal, arena, y áridos cerámicos de ladrillos triturados conocidos como cocciopesto. En la observación macroscópica de las muestras, se observaron diversos fragmentos de huesos de animales de pequeñas-medianas dimensiones, en cantidades más pequeñas pero mezclados con los áridos. Estos fragmentos aparecen en las capas exteriores e intermedias de los revestimientos de mortero. En este trabajo se presentan los resultados de la caracterización macroscópica de los morteros y una propuesta metodológica de estudio de este tipo de residuo material, basada en la arqueometría y centrada en la proporción de fragmentos de hueso con respecto al peso total de las muestras, su representatividad con respecto a las capas constructivas y la probable relación entre la presencia de huesos en la mezcla con la funcionalidad de las estructuras industriales de La Magdalena.

Palablas-clave: La Magdalena. Mortero. Signinum. Fauna. Época romana.

\section{Abstract}

1, 2 Pablo Guerra-García ${ }^{1}$ Universidad Politécnica de Madrid ${ }_{2}^{2}$ Trébede Patrimonio y Cultura S.L. Madrid - Spain

${ }^{3}$ Felipe Gómez-Moreno ${ }_{3}^{3}$ Trébede Patrimonio y Cultura S.L. Madrid - Spain

${ }^{4}$ César Manuel Heras-Martínez 4Universidad Cumplutense de Madrid Madrid - Spain

${ }^{5}$ Ana Bastita-Ramírez ${ }^{5}$ Trébede Patrimonio y Cultura S.L. Madrid - Spain

Recebido em 08/12/17

Aceito em 05/06/18
The archaeological site of La Magdalena, located in Alcalá de Henares (Spain), is a complex formed by several industrial, storage and housing structures from the Roman Era. During archaeological intervention, different industrial structures were documented. Those structures were built using different types of lime mortar, from the foundations - opus caementicium - to the final cover - opus signinum. In general, they all follow the same Roman construction guidelines, using lime, sand, and ceramic aggregates of crushed bricks known as cocciopesto. However, in the macroscopic observation of the samples, several small and medium fragments of animal bones were detected in the matrix of the lime, mixed with the lime, although in smaller quantities. The average size of the fragments ranges from half a millimetre to one centimetre in length. These fragments were present in the outer and middle layers of the mortar coatings. In this project, the results are shown as quantitative marks. This study also presents a methodological proposal for the study of this type of material waste, based on archaeometry and focused on the proportion of bone fragments in relation to the total weight of the samples, the representativeness of the fragments analysed in relation to the constructive layers, and the probable relation between the presence of bones in the mixture with the functionality of the industrial structures of La Magdalena.

Keywords: La Magdalena settlement. Mortar. Signinum. Fauna. Roman age. 


\section{Introducción}

El yacimiento arqueológico de La Magdalena se encuentra en el municipio de Alcalá de Henares, dentro de la Comunidad de Madrid. Su ubicación geográfica corresponde al corredor natural del Henares, una zona de llanura aluvial enmarcada dentro de la primera terraza del río Henares (Figura 1).

Entre los años 2007 y 2017, la empresa Trébede, Patrimonio y Cultura S.L. y el área de Antropología Física dela UAH desarrollaron excavaciones arqueológicas en Alcalá de Henares.
Durante la intervención se determinó la presencia de un basto complejo arqueoantropológico denominado La Magdalena y que estaba compuesto, entre otros, por varias necrópolis de cronologías diversas (campaniforme y edad del bronce, altoimperial,bajoimperial, tardorromana e hispanovisigoda), un amplio complejo industrial da época romano altoimperial y una zona de servicio hispano-romana, pero con uso en época visigoda y una fase de uso y aprovechamiento en época medieval, moderna y contemporánea.

\section{Figura 1 - Localización del yacimiento de La Magdalena (Alcalá de Henares, Madrid)}

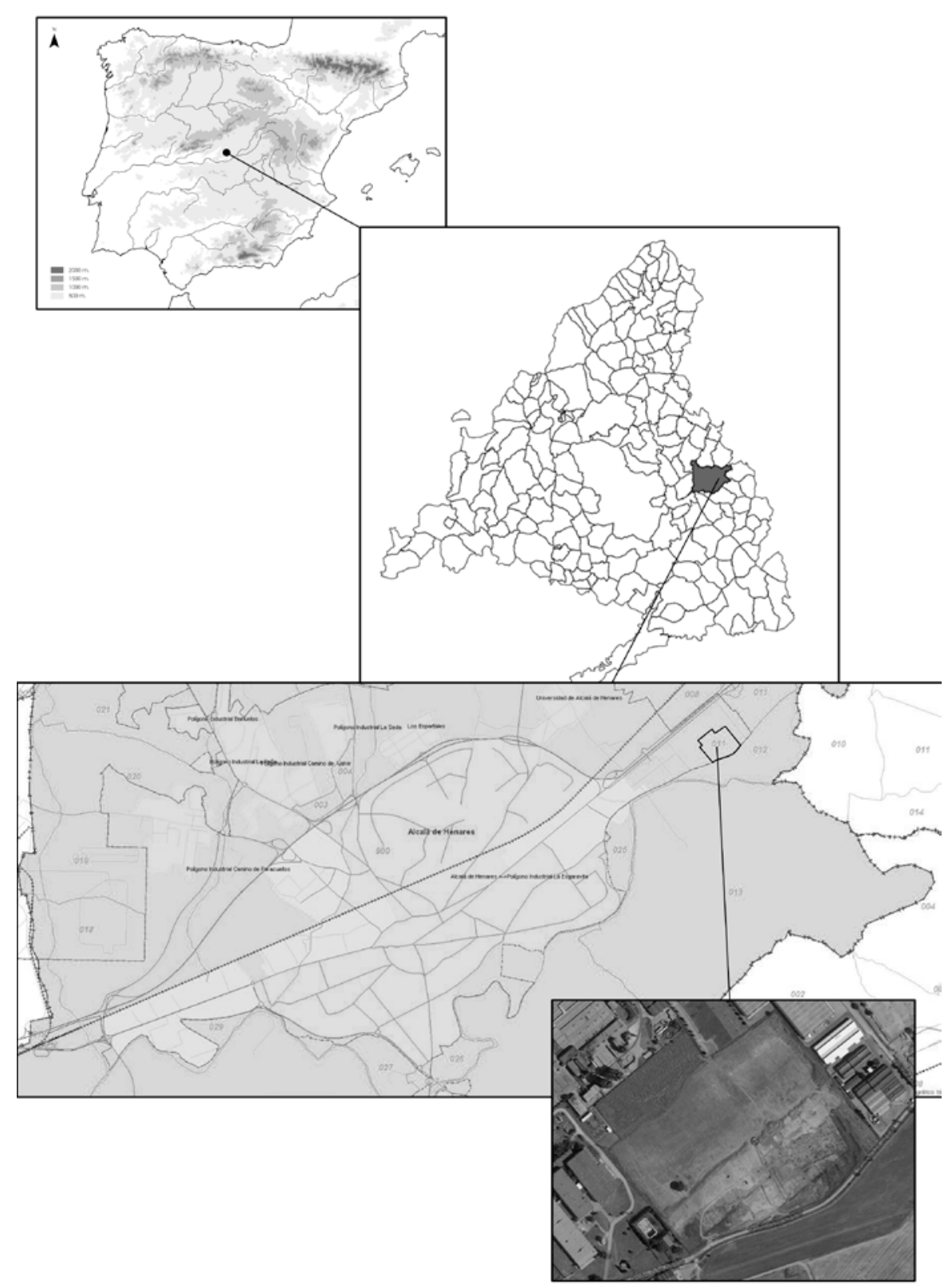

Fuente: Trébede Patrimonio y Cultura S.L.

34 Guerra-García, P.; Gómez-Moreno, F.; Heras-Martínez, C. M.; Bastita-Ramírez, A. 
En el año 2011 el equipo dirigido por César Heras, Virginia Galera y Ana Bastida, de la empresa Trébede, Patrimonio y Cultura S.L. y en colaboración con la Universidad de Alcalá, solicitó el estudio de los morteros documentados durante la intervención arqueológica desarrollada en el yacimiento de La Magdalena. Las fases romanas (a las que se adscriben los materiales analizados) se corresponden con una posible ocupación primero industrial de distribución y, posteriormente, rural de época romana, con distintos espacios destinados al uso productivo y funerario (HERAS MARTÍNEZ et al., 2012). Tras una rápida visualización de las estructuras, se pudo comprobar que, efectivamente, varias de ellas contaban con revestimientos de mortero con adiciones cerámicas y con presencia de fragmentos de hueso, muy abundantes en algunas capas constructivas de las estructuras, que son depósitos destinados al almacenamiento de productos líquidos o semilíquidos.

La primera estructura - EMG1 - responde a un tipo de cubeta de decantación, con un desplome en una de sus laterales por un movimiento sísmico. Con dimensiones de $4,1 \times 3,5 \mathrm{~m}$, orientación $\mathrm{NW}$ SE y potencia conservada media y máxima de entre 40 y $45 \mathrm{~cm}$, se adscribe a un momento entre Claudio II, El Gótico (268-270 d.C.) y Constantino I, El Grande (307-337 d.C.), aunque, por los materiales, la dirección arqueológica se decanta más por una cronología vinculada a la época de Diocleciano (284-305 d. C.).

La segunda estructura - EMG2 - es una pileta de dimensiones más reducidas $(3,8 \times 1,55 \mathrm{~m})$ con respecto a la anterior y está situada en el mismo contexto industrial. Se trata de una cuneta con orientación NW-SE, dimensiones interiores de $3,55 \times 1,0 \mathrm{~m}$. Su peculiaridad es que tiene dos suelos, uno de $47 \mathrm{~cm}$ de potencia, adscrito a la época de Vespasiano (70-74 d. C.), y un segundo suelo de $62 \mathrm{~cm}$ de potencia, creado bajo gobierno de Claudio II, El Gótico (268-270 d.C.).

La última estructura - EGM3 - corresponde a un depósito tipo castellum aquae de dimensiones exteriores (tendencia cuadrangular) de 2,37×2,18 $\mathrm{m}$, orientación NE-SW y dimensiones interiores de $1,75 \times 1,66 \mathrm{~m}$. Su potencia media es de $38 \mathrm{~cm} \mathrm{y}$ estaría adscrito a algún momento entre Tiberio (14-37 d. C.) y Calígula (37-41 d.C.), pero más cercano al primero (25-30 d.C.).

A continuación, la Figura 2 presenta las tres estructuras mencionadas.

De cada estructura se tomaron dos muestras de los paramentos principales, formados por revestimientos de mortero de cal con árido silíceo y cerámico, además de fragmentos óseos en menor o mayor cantidad.

Figura 2 - Detalle de las tres estructuras hidráulicas con morteros analizadas: EMG1 (arriba izquierda), EMG2 (derecha) y EMG 3 (abajo izquierda)
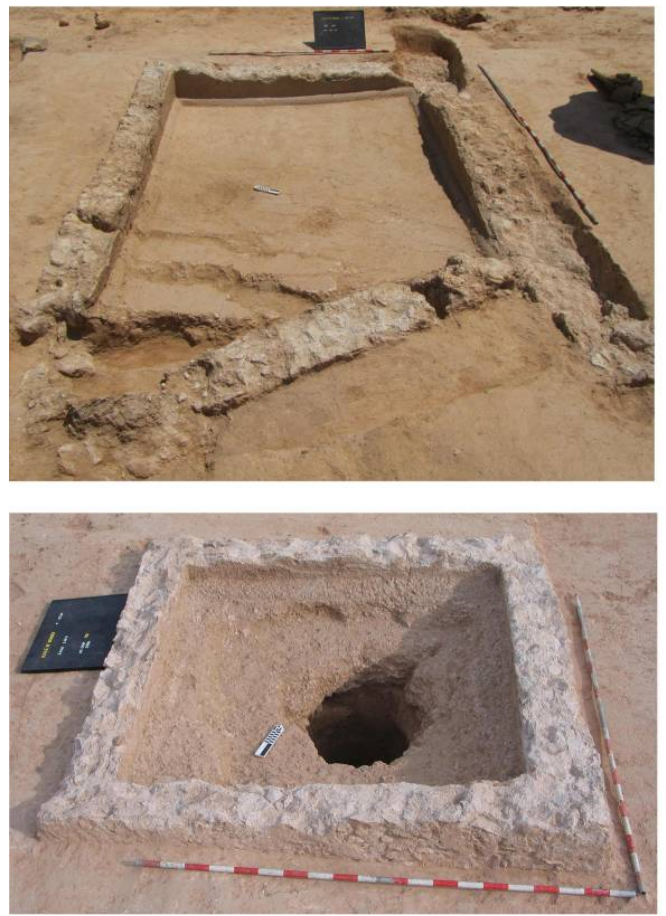

Fuente: Trébede Patrimonio y Cultura S.L.

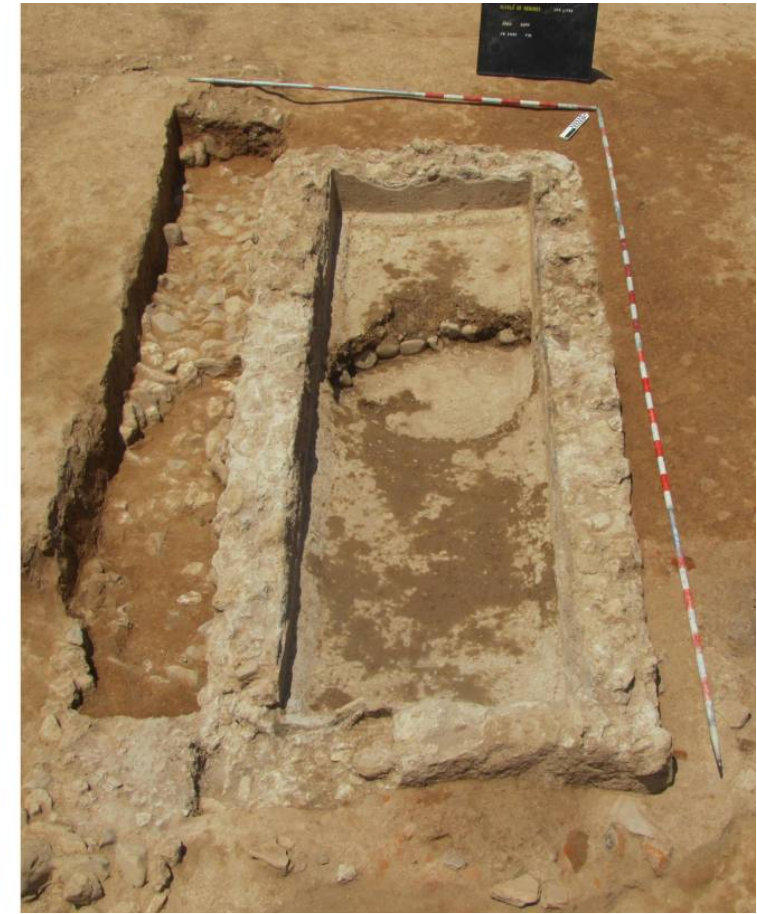


La incorporación de fragmentos de hueso y otros aditivos orgánicos era muy frecuente en mezclas antiguas, tal y como lo indican los últimos estudios relativos a la presencia de estos componentes, con referencias incluso en el continente americano (REBOUÇAS, 1885), por lo que no resulta novedosa la identificación de este tipo de material (ALEJANDRE SÁNCHEZ, 2002; ÁLVAREZ GALINDO et al., 1995). Algunos investigadores destacan las cualidades que aportan los materiales orgánicos a los morteros y a otros tipos de argamasas (ROBERGE, 2016). Además de permitir la datación por radiocarbono ${ }^{14} \mathrm{C}$ (ALBASHAIREH; HODGINS, 2011), estos pueden modificar las cualidades físico-mecánicas de las mezclas (SICKELS, 1981). En lo que respecta a las muestras analizadas, se destaca la distribución de los fragmentos óseos en algunas capas constructivas y, sobre todo, la identificación del tipo de material óseo (parte del esqueleto proximal o distal)

La Figura 3, a continuación, muestra una secuencia microestratigráfica constructiva de la estructura EMG3 en la cual se pueden apreciar las diferentes capas de las que se han tomado las muestras.

\section{Metodología}

Para el muestreo de morteros se seleccionaron tres estructuras de carácter industrial, documentadas en el área de producción y cuya fábrica estaba compuesta por una o más capas de morteros. Se sabe que este tipo de estructuras corresponden a piletas y cubetas destinadas a almacenar alguna clase de líquido, como aceites (torcularium) o vinos (lacus o calcatorium). Aunque este proceso constructivo ya fue defendido en una tesis doctoral (GUERRA GARCÍA, 2015) aportando paralelos interesantes desde el punto de vista de las técnicas edilicias y comparando los sistemas de construcción con otros parecidos en Europa (MAYS et al. 2013), estas estructuras parten de una cimentación excavada en el substrato, seguida de un encamado de gravas de diversa granulometría para encofrar las paredes con al menos dos capas de mortero base - opus incertum, opus caementicium - y, finalmente, dos capas de un revestimiento tipo opus signinum con aportes orgánicos (GUERRA GARCÍA et al., 2017). Este tipo de estructuras ha sido documentado en todo el Occidente Europeo y en el Oriente Próximo (DE ALMEIDA et al., 2012; ROBINSON, 2006; GOREN; GORING-MORRIS, 2008). El potencial hidráulico del revestimiento exterior del edificio se hizo con un árido cerámico denominado cocciopesto, que consiste en fragmentos de ladrillos y tejas trituradas en distintas dimensiones y diferentes proporciones.

Figura 3 - Secuencia microestratigráfica constructiva de la estructura EMG3

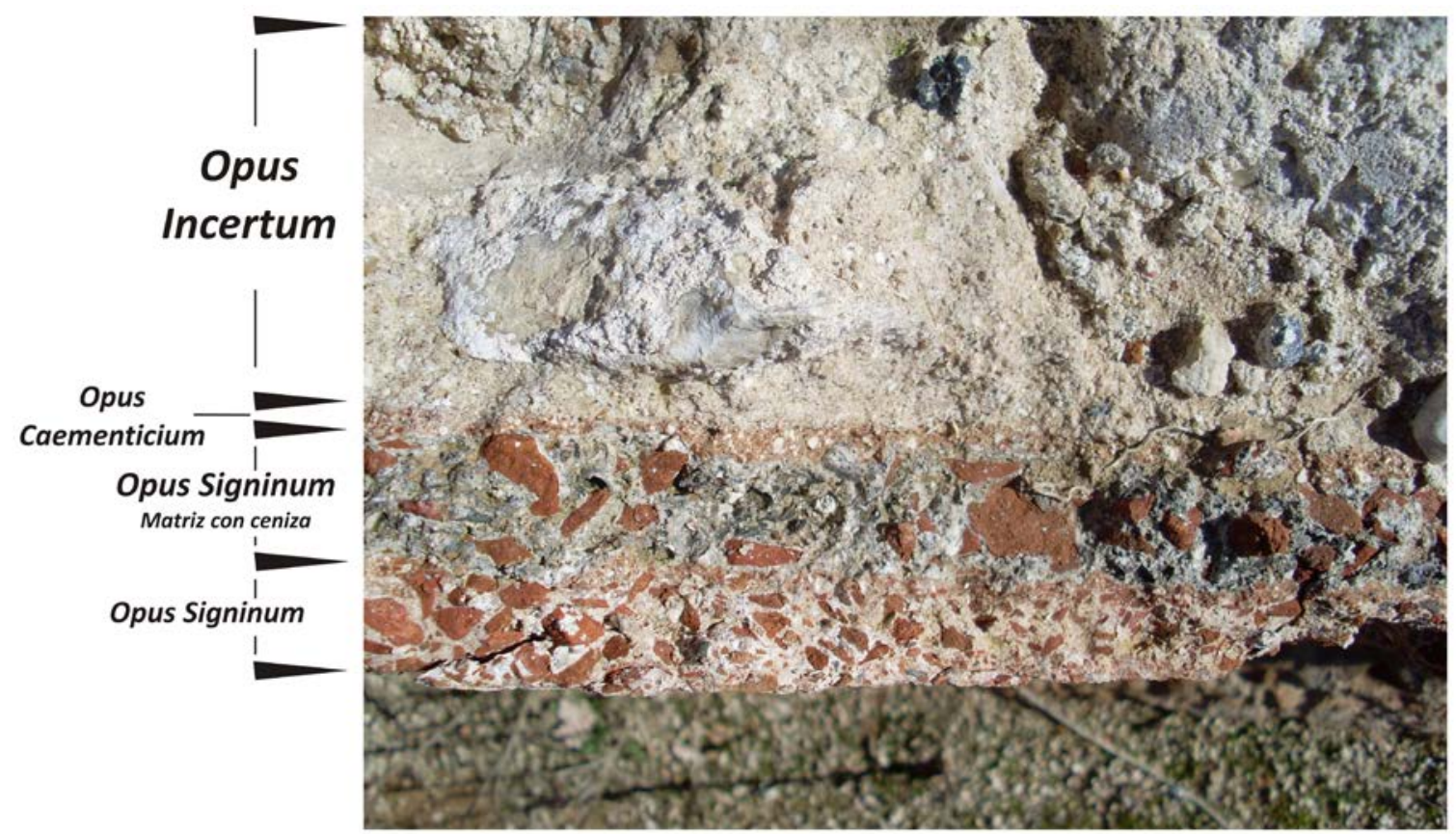

Fuente: Guerra García (2015). 
En lo que respecta a las muestras en sí, las MG1 y MG2 fueron extraídas de la pared lateral y de la base de una gran cubeta o piscina de decantación denominada EMG1. A simple vista, la estructura se configura por medio de unas cimentaciones a modo de opus incertum. Una vez observado el estado y las condiciones del revestimiento de mortero, se determinaron los puntos de muestra. La muestra tomada estaba constituida por un opus signinum bien armado y con áridos distribuidos de forma ordenada. En la extracción se observó que la capa de signinum se apoyaba sobre una segunda fábrica de mortero a modo de cama de cal con áridos y cenizas.

Por su parte, las muestras MG3 y MG4 fueron extraídas de la estructura EMG2, una pileta situada a pocos metros de la estructura anterior, de forma rectangular y con una configuración constructiva similar: opus incertum en la cimentación de fosa excavada en el sustrato natural y una sucesión de revestimientos de opus caementicium y signinum, de los que se han tomado las muestras.

De las dos muestras mencionadas, la MG4 fue tomada de un suelo inferior, correspondiente a una primera fase de uso y reparado en un determinado momento, sobre el cual se apoya un segundo piso del cual se tomó la muestra MG3. Esta segunda muestra se tomó de uno de los laterales del interior de la estructura, al contacto con una media caña presente entre el suelo y la pared. Se trataba de un mortero de cal con áridos y adiciones cerámicas muy compacto durante la manipulación.

Finalmente, de la estructura EMG3 se extrajeron dos muestras, la MG5 y la MG6. Esta estructura fue identificada como un castellum aqvae por parte del equipo arqueológico. Su emplazamiento se encuentra bastante distante de las estructuras anteriores, y su planta cuadrada se completa con un agujero de amortización en el centro. El sistema de construcción es muy similar a los anteriores: cimentación consistente en un opus incertum, una capa de opus caementicium y revestimiento de opus signinum. La cimentación tenía muy poca profundidad y su estado de conservación era precario. La muestra MG5 fue tomada de uno de los laterales de la estructura, mientras que la MG6 se extrajo del suelo. Ambas muestras presentaban un buen aspecto en cuanto a la consistencia. La inspección inicial indicó que ambas estaban constituidas por morteros de cal con áridos y aditivos cerámicos de gran tamaño, distribuidos de forma irregular.

La extracción, manual en todos los casos (Figura 4), ha seguido los protocolos del RILEM sobre muestreo para materiales inorgánicos, apoyados por los trabajos de Bartoset al. (2000) y combinados con los procedimientos de Doebley y Spitzer (1996). Una vez señalizada el área de extracción y habiéndola fotografiada previamente, se procedió a la retirada de las primeras capas con una espátula, a fin de eliminar posibles componentes orgánicos y/u otros materiales que pudiesen alterar el análisis. La limpieza de las muestras se llevó a cabo, en primer lugar, por limpieza mecánica en seco, a fin de evitar la pérdida de algún tipo de pigmentación. Finalmente se aplicó una limpieza con agua corriente. El pesaje de las muestras extraídas se llevó a cabo por medio de una báscula digital de precisión con un rango de pesaje de $0,1 \mathrm{~g}$. hasta $1.000 \mathrm{~g}$.

\section{Figura 4 - Extracción mecánica de las muestras en el yacimiento de La Magdalena}
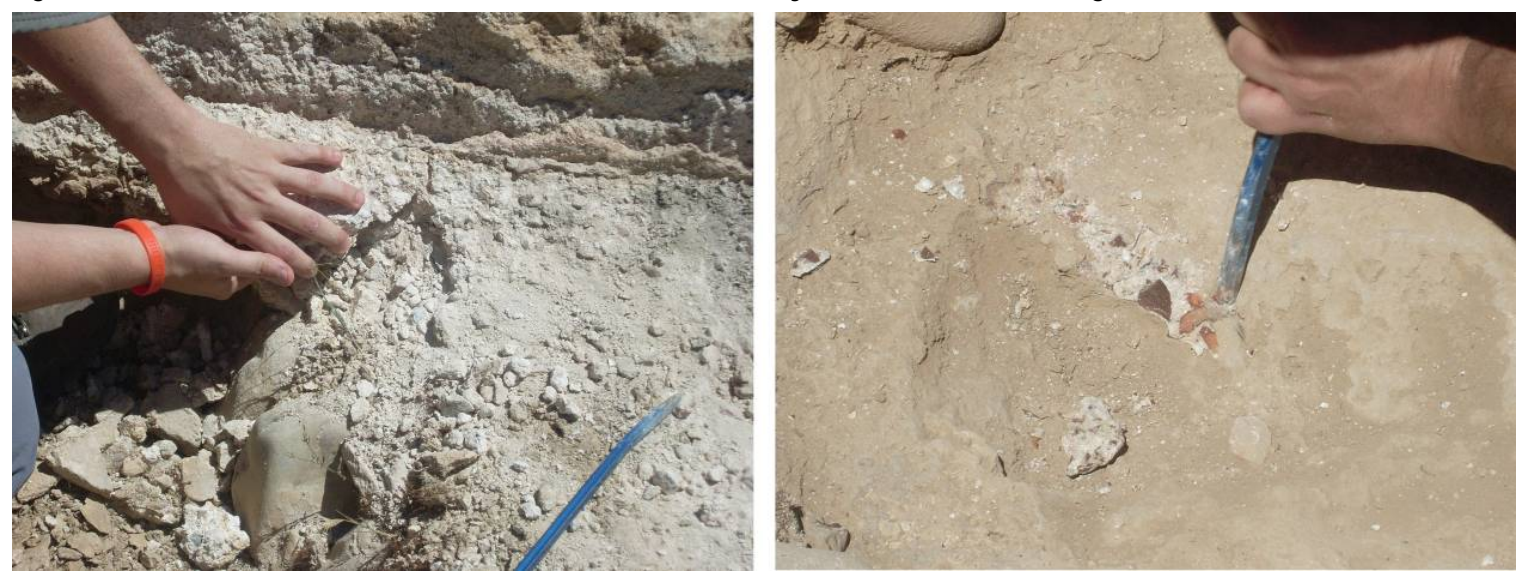

Fuente: Trébede Patrimonio y Cultura S. L. 
Una vez realizada la extracción y la documentación de las muestras, se procedió al análisis de los materiales, la metodología y el procedimiento que queda reflejado en el presente trabajo junto con los resultados finales del análisis y las conclusiones. Existen algunos precedentes que han servido como guía para este estudio, pues los análisis efectuados se basan en metodologías macroscópicas empleadas en el análisis de morteros como puntos de partida para analizar los morteros química o mineralógicamente (MIDDENDORF et al., 1999; BINICI et al., 2010).

Esta secuencia analítica se ha basado en una metodología macroscópica presente en una abundante bibliografía basada en el estudio y la caracterización de los morteros históricos (BALBÁS et al., 2002; INGHAM, 2010). La diferencia con métodos como los microscópicos es que las muestras se analizan en estado crudo, es decir, sin desarrollar una lámina delgada que permite realizar una microscopía óptica polarizada (ELSEN, 2006).

En cuanto a los estudios estadísticos y de resultados cuantitativos, se han seguido algunas pautas de trabajos de investigación similares, que cuantifican la presencia de áridos y de otros elementos presentes en los morteros, tales como áridos cerámicos o adiciones puzolánicas (GONZÁLEZ CORTINA, 2000; GUERRA GARCÍA, 2015). En este sentido, ha resultado muy útil el trabajo llevado a cabo por Applied Petrography Group en cuanto a petrografía e identificación de componentes en morteros (LESLIE; EDEN, 2008). Para interpretar los parámetros se han cruzado los datos arqueológicos con los datos arqueométricos, de tal forma que el cálculo porcentual se ha desarrollado en relación con las fases constructivas y con las estructuras documentadas. En la actualidad hay diversos antecedentes de estudios similares realizados (MIRIELLO, 2010; BARONIO et al., 1999).

Una vez terminado este tratamiento se procedió a la visualización de las muestras por medio de un microscopio USB Veho modelo VMS-004 con aumentos 20×400 e iluminación de ocho LED. El tratamiento de las imágenes y el escalado de las mismas se llevaron a cabo por medio del programa JMICROVISION 1.2.7. Todo el proceso analítico y de tratamiento de muestras se llevó a cabo en las instalaciones de la empresa Trébede Patrimonio y Cultura S.L.

El tratamiento de los datos se realizó con el programa estadístico SPSS 15.0; ya para la creación de gráficas, se contó con la ayuda del paquete Office. Los análisis estadísticos realizados se han basado principalmente en la obtención de las frecuencias absolutas y relativas de presencia de material óseo y dental, así como la comparación de estos valores a través de diferentes criterios tipología del material, procedencia de las muestras por estructura y por opera y dimensiones de las evidencias. Las pruebas estadísticas realizadas son el test no paramétrico U de Mann-Whitney, para muestras independientes, y el análisis de correspondencias, para la relación de muestras mediante la prueba $\chi^{2}$.

Por último, se planteó una fórmula para realizar comparaciones en futuros estudios de morteros que permite establecer un cálculo sencillo y directo de la densidad de material óseo y dental en diversas muestras, con independencia de la cantidad de material que se extraiga. La única consideración es el fraccionamiento de las muestras a tamaños pequeños para poder observar la mayor cantidad de evidencias. De esta forma, la relación se establece a partir de la cantidad de huesos por cada 100 g de mortero revisado.

\section{Resultados y discusiones Observación macroscópica}

Se documentaron en total 150 fragmentos óseos en las muestras de mortero analizadas, muestras que corresponden con las tres estructuras hidráulicas explicadas en el punto anterior. En líneas generales, el material identificado predominante es el óseo, mientras que, del total de los fragmentos, sólo seis muestras corresponden a piezas dentales (Figura 5). Es importante tener en cuenta que la mayoría de las muestras son sólo impresiones dejadas en el mortero de cal, puesto que el mineral de los huesos ha sido degradado hasta desaparecer.

\section{Porcentajes}

Teniendo en cuenta las tres estructuras analizadas, las siguientes gráficas mostrarían la distribución de los fragmentos identificados. Tal como se observa en el gráfico correspondiente a la Figura 6, el 20\% de los huesos pertenece a la estructura EMG1; el 42,7\% corresponde a la estructura EMG2; y, finalmente, el 37,3\% es de la estructura EMG3. En esta misma imagen puede observarse cómo los huesos de sección redonda son más comunes en las estructuras EMG1 y EMG3, mientras que los huesos de sección plana son mayoritarios en la estructura EMG2. Por su parte, las piezas correspondientes con las dentales sólo aparecen en las estructuras EMG1 (cuatro piezas) y EMG3 (dos piezas). 
Figura 5- Gráfica porcentual con los porcentajes totales por el tipo de sección de los huesos

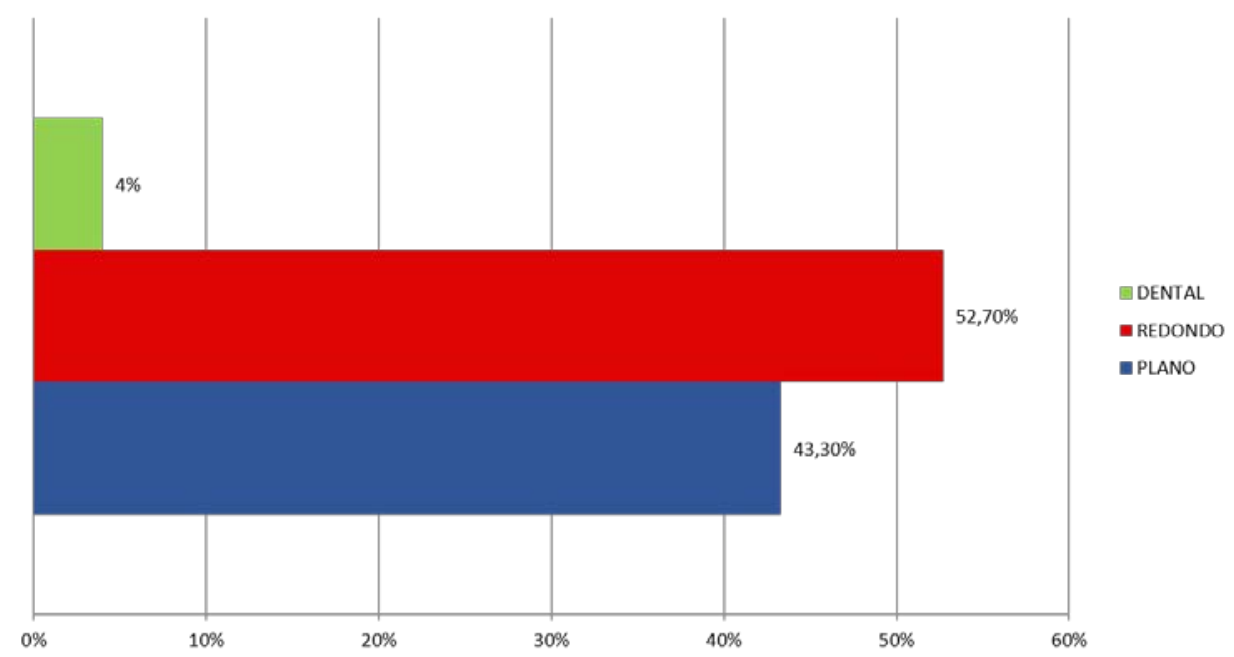

Fuente: Trébede Patrimonio y Cultura S. L.

Figura 6-Gráfica porcentual de los fragmentos analizados con respecto a las estructuras

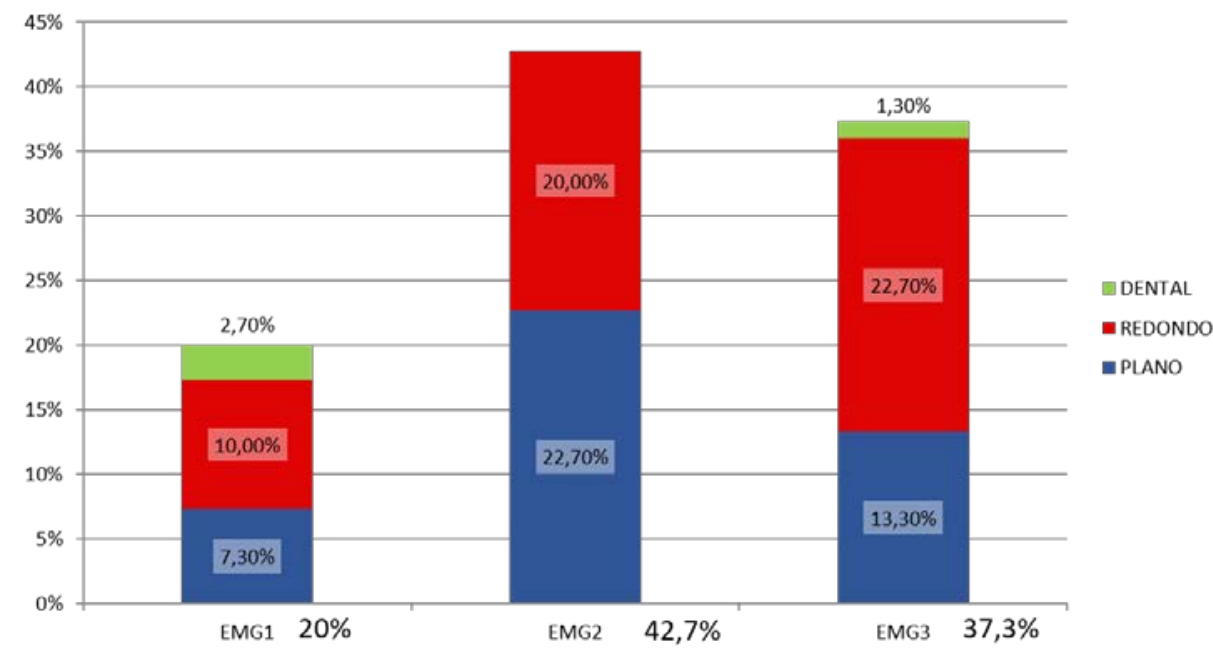

Fuente: Trébede Patrimonio y Cultura S.L.

Figura 7 - Gráfica con los porcentajes según el tipo de opera

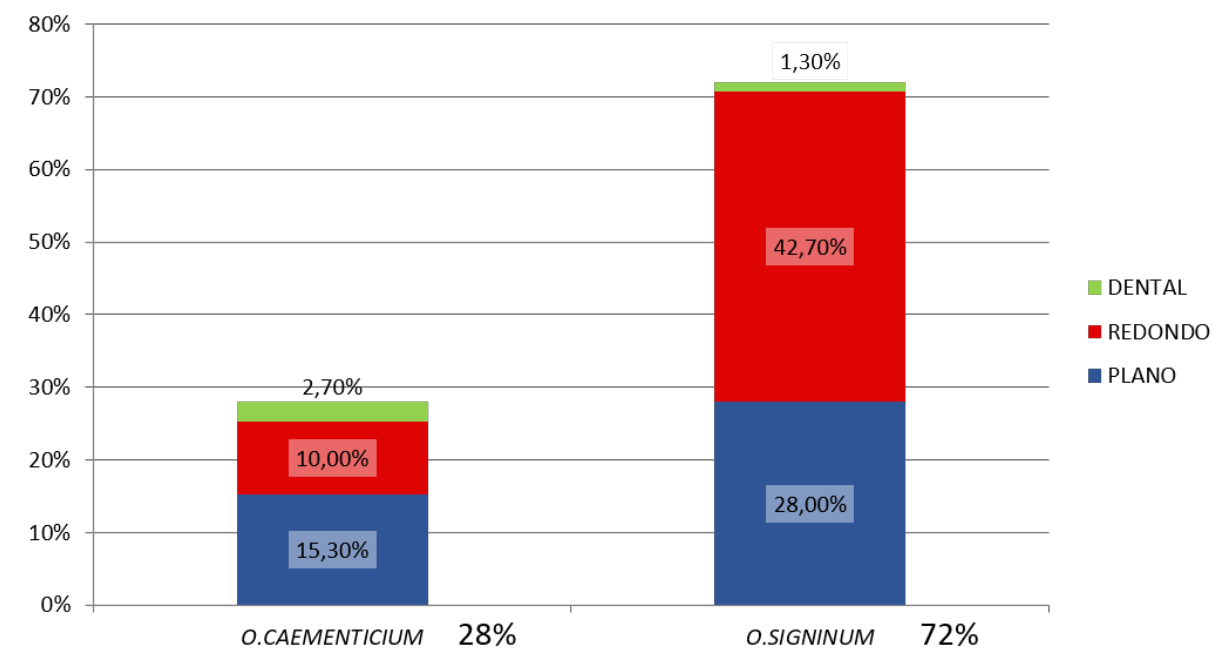

Fuente: Trébede Patrimonio y Cultura S. L. 
Por último, se observa que la representación de los huesos según su forma es más abundante para los fragmentos con sección redonda frente a los planos en el opus signinum, siendo muy parecidos los encontrados en el opus caementicium. Con respecto a los dentales, se encuentran dos en el opus signinum y cuatro en el opus caementicium (Figura 7).

En cuanto al análisis estadístico de los datos, la forma de los huesos no ha presentado valores significativos entre la sección de los fragmentos y el origen de la muestra. Sin embargo, sí se ha apreciado cierta correlación entre los porcentajes globales de huesos con el tipo de mortero en el que se han documentado. El análisis estadístico U de Mann-Whitney muestra diferencias muy significativas en los porcentajes por forma de los fragmentos ( $\mathrm{p}<0,0001)$ y el tipo de opera ( $\mathrm{p}$ $<0,0001$ ). En términos globales, el mortero del tipo opus signinum ha presentado más fragmentos correspondientes a microfauna (72\%) que el mortero del tipo opus caementicium (28\%). Por tipo de opera, los fragmentos de hueso con sección plana y las piezas dentales tienen más presencia en el opus caementicium, mientras que los huesos de sección redonda son más abundantes en el opus signinum.

\section{Tamaño de los huesos}

Atendiendo a los datos obtenidos sobre los tamaños observados, el valor medio es de 4,95 mm, teniendo fragmentos con un mínimo de 0,86 mm y un máximo de 23,79 mm, correspondiente a una pieza dental (Figura 8).
Los análisis estadísticos mediante el test $\mathrm{U}$ de Mann-Whitney desarrollados en este estudio han demostrado que existen diferencias muy significativas entre el tamaño de los huesos y la forma y el origen de la muestra o tipo de opera (todas ellas $\mathrm{p}<0,0001$ ).

Como puede observarse en la Figura 9a, el mayor rango de dimensiones presente en la estructura EMG1 se debe a la presencia de piezas dentales, las cuales, sin embargo, constituyen un porcentaje mínimo con respecto al total de fragmentos. En lo que se refiere a los fragmentos de sección plana y redonda, las piezas analizadas poseen dimensiones similares. Por su parte, con respecto a las mediciones según el tipo de opera (Figura 9b), los resultados en cuanto a la desviación estándar son muy similares entre los fragmentos de opus caementicium y de opus signinum, por lo que no se han encontrado diferencias significativas.

Por último, el análisis de correspondencias muestra cómo los huesos, por su forma, se asocian con las estructuras (Figura 10). Así, los huesos redondos se relacionan con la estructura EMG3, los huesos planos lo hacen con la estructura EMG2 y los dentales quedan marginados sin poder ser asociados a ninguna de las estructuras. La primera dimensión (tamaño) explica el $70 \%$ de estas relaciones, mientras que la segunda (estructura) explica un $15 \%$.

A continuación, en las Figuras 11, 12 y 13, se pueden ver en detalles algunos de los fragmentos de huesos encontrados en las estructuras EMG 1, EMG2 y EMG3, respectivamente.

\section{Figura 8 - Gráfica de la desviación estándar general de los fragmentos analizados por sección}

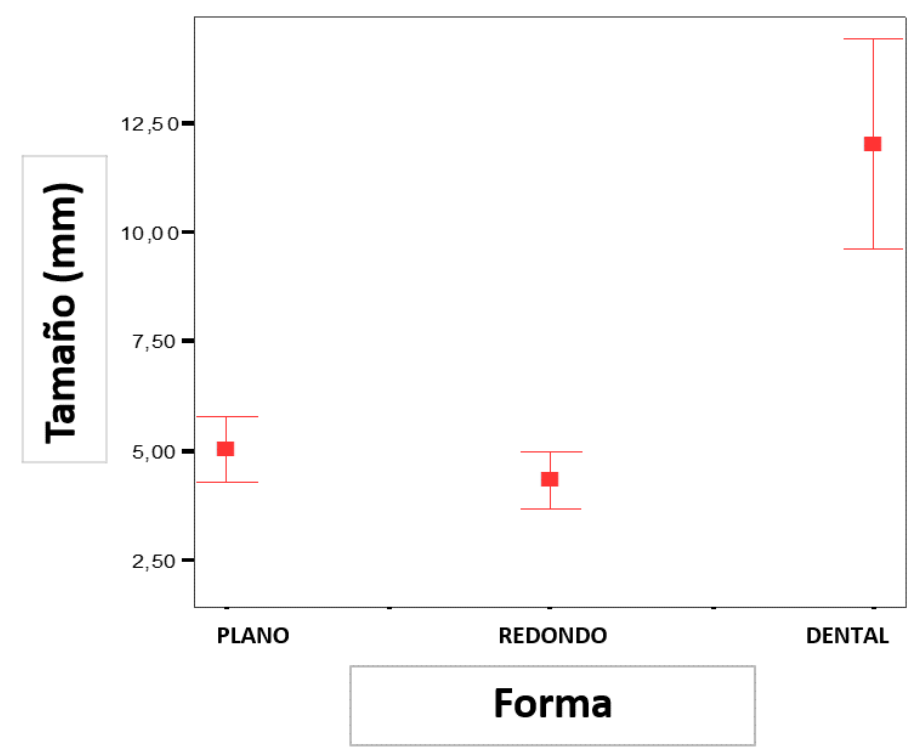

Fuente: Trébede Patrimonio y Cultura S.L. 
Figura 9 - Gráficas correspondientes a la desviación estándar de las dimensiones por tipo de opera (a) y distribución de los fragmentos con sus dimensiones en función de las variables estructura/sección (b)

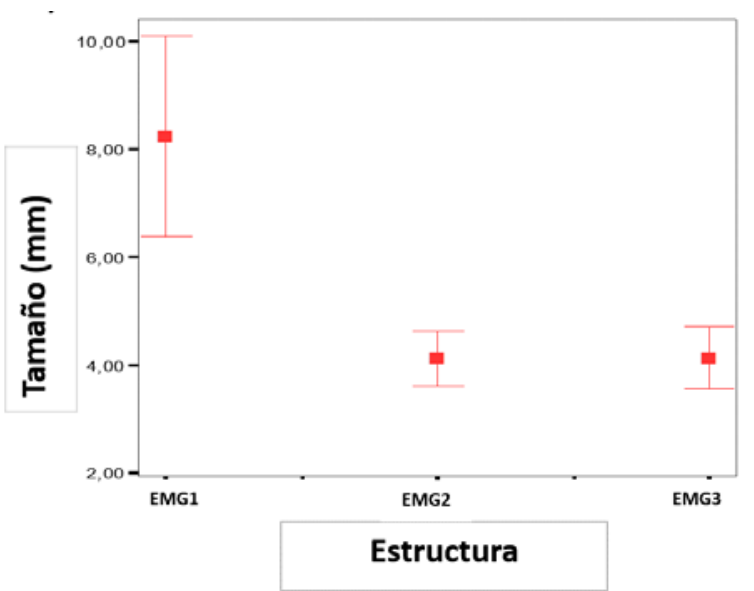

(a)

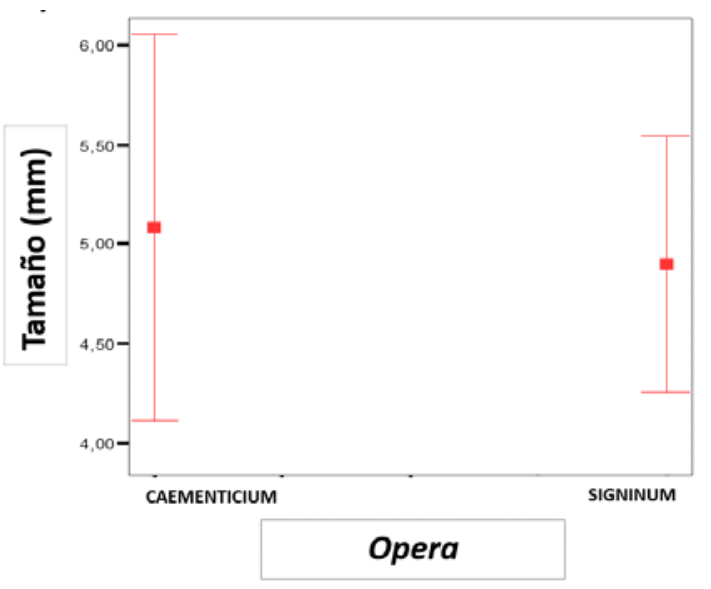

(b)

Fuente: Trébede Patrimonio y Cultura S. L.

Figura 10 - Gráfica con los resultados del análisis de correspondencias en el que se asocian los huesos según su forma con las estructuras

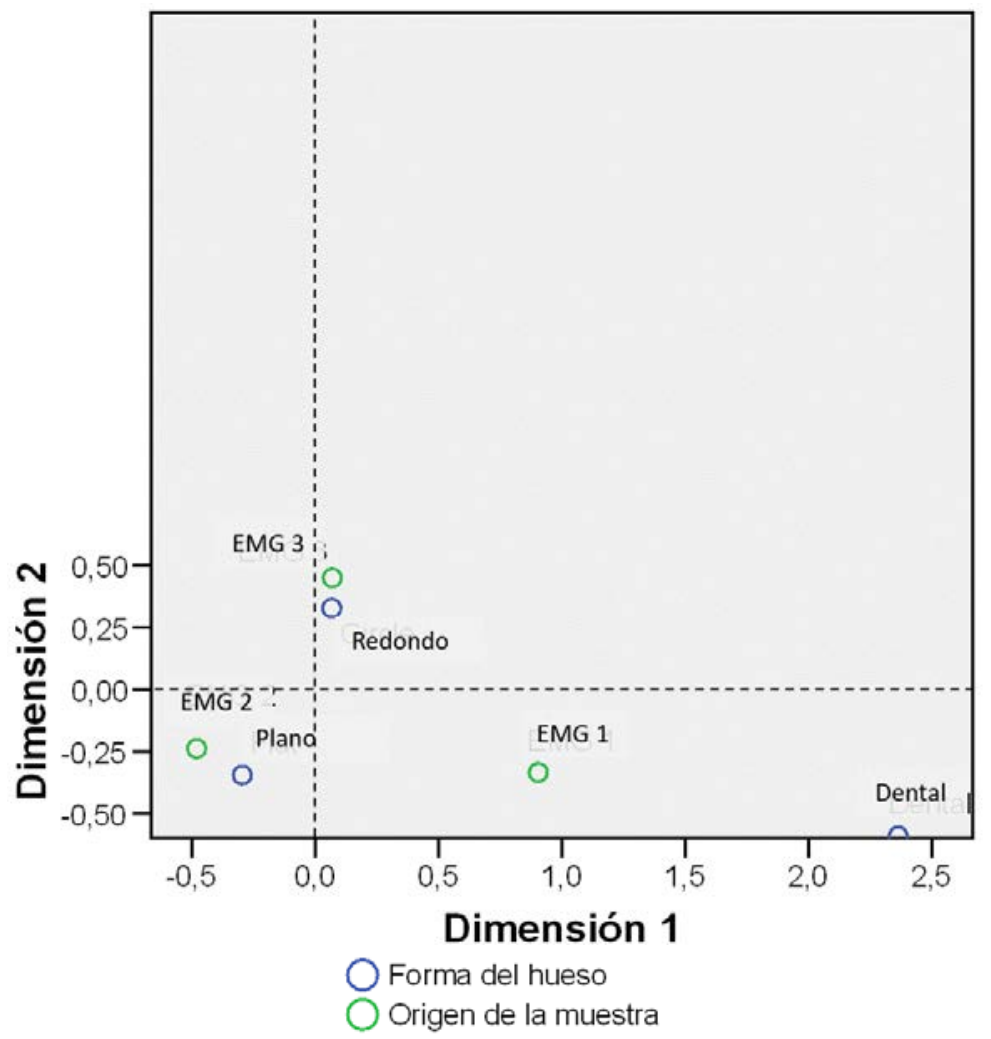

Fuente: Trébede Patrimonio y Cultura S. L. 
Figura 11 - Imagen correspondiente a un fragmento de hueso de gran tamaño, encontrado en la estructura EMG1, dentro de un opus signinum

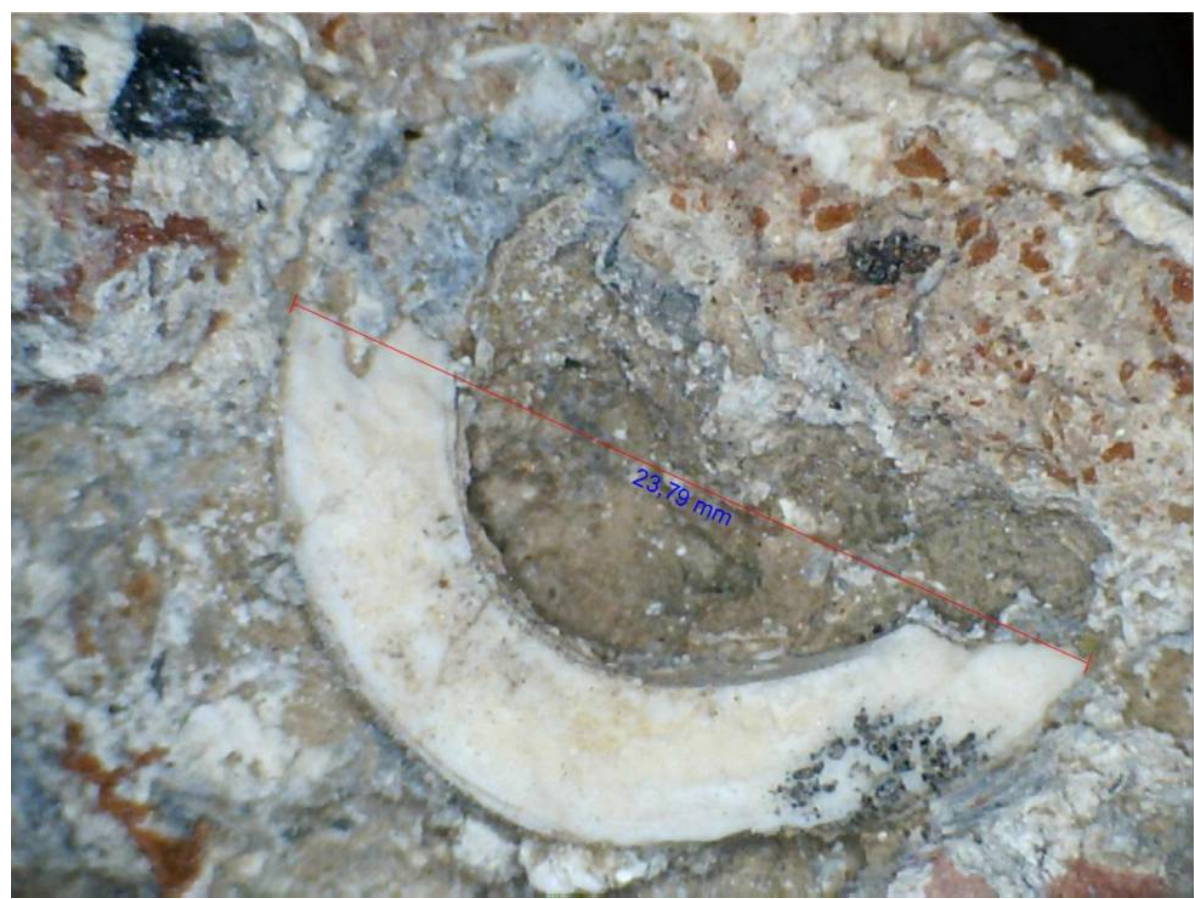

Fuente: Trébede Patrimonio y Cultura S.L.

Figura 12 - Detalle de diferentes fragmentos de hueso identificados en las muestras MG3 y MG4 de la estructura EMG2, mezclados con fibras orgánicas y carbones, entre otros
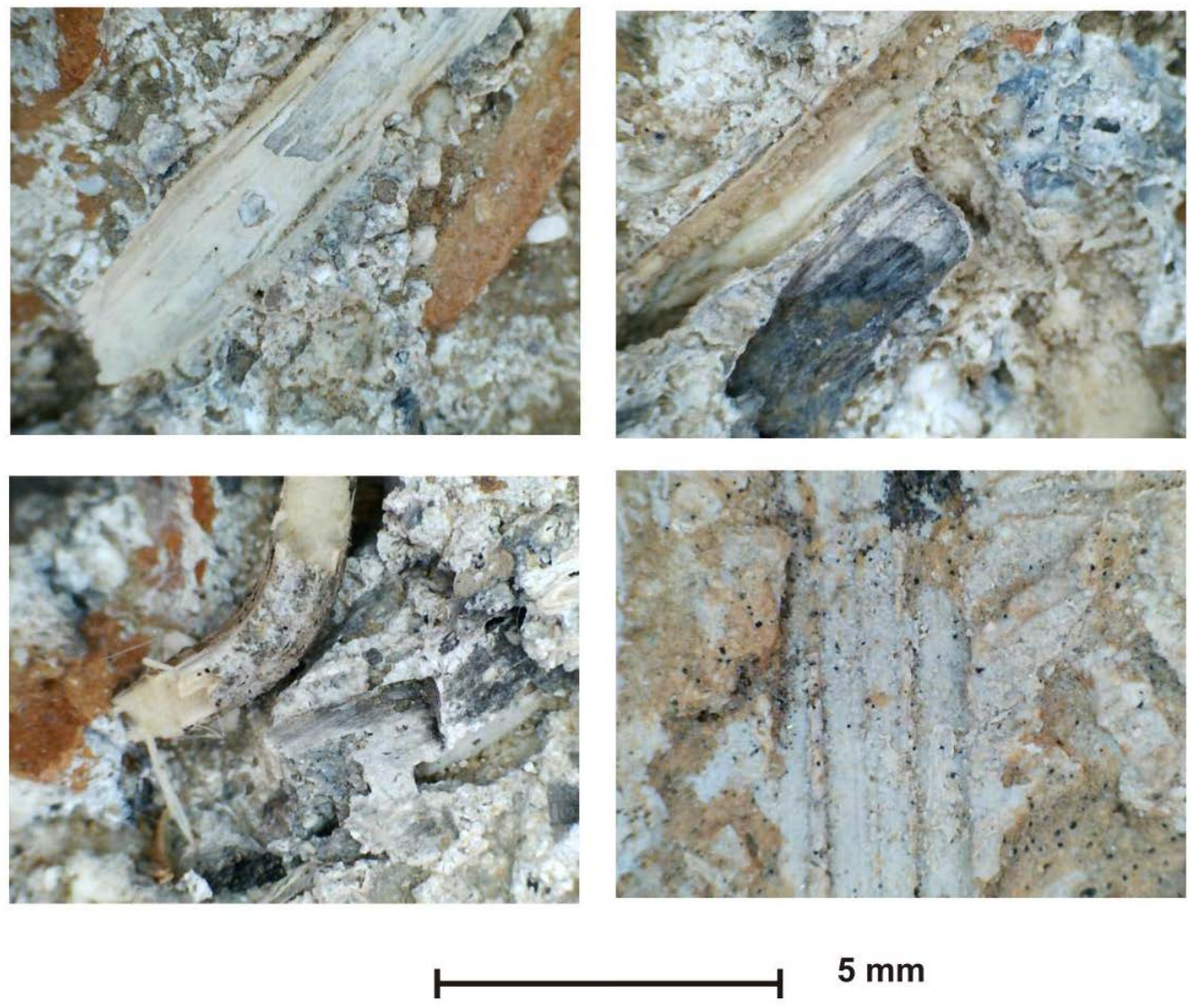

Fuente: Trébede Patrimonio y Cultura S.L.

42 Guerra-García, P.; Gómez-Moreno, F.; Heras-Martínez, C. M.; Bastita-Ramírez, A. 
Figura 13 - Imagen correspondiente a una impronta de hueso, encontrada en la estructura EMG3, en un opus signinum

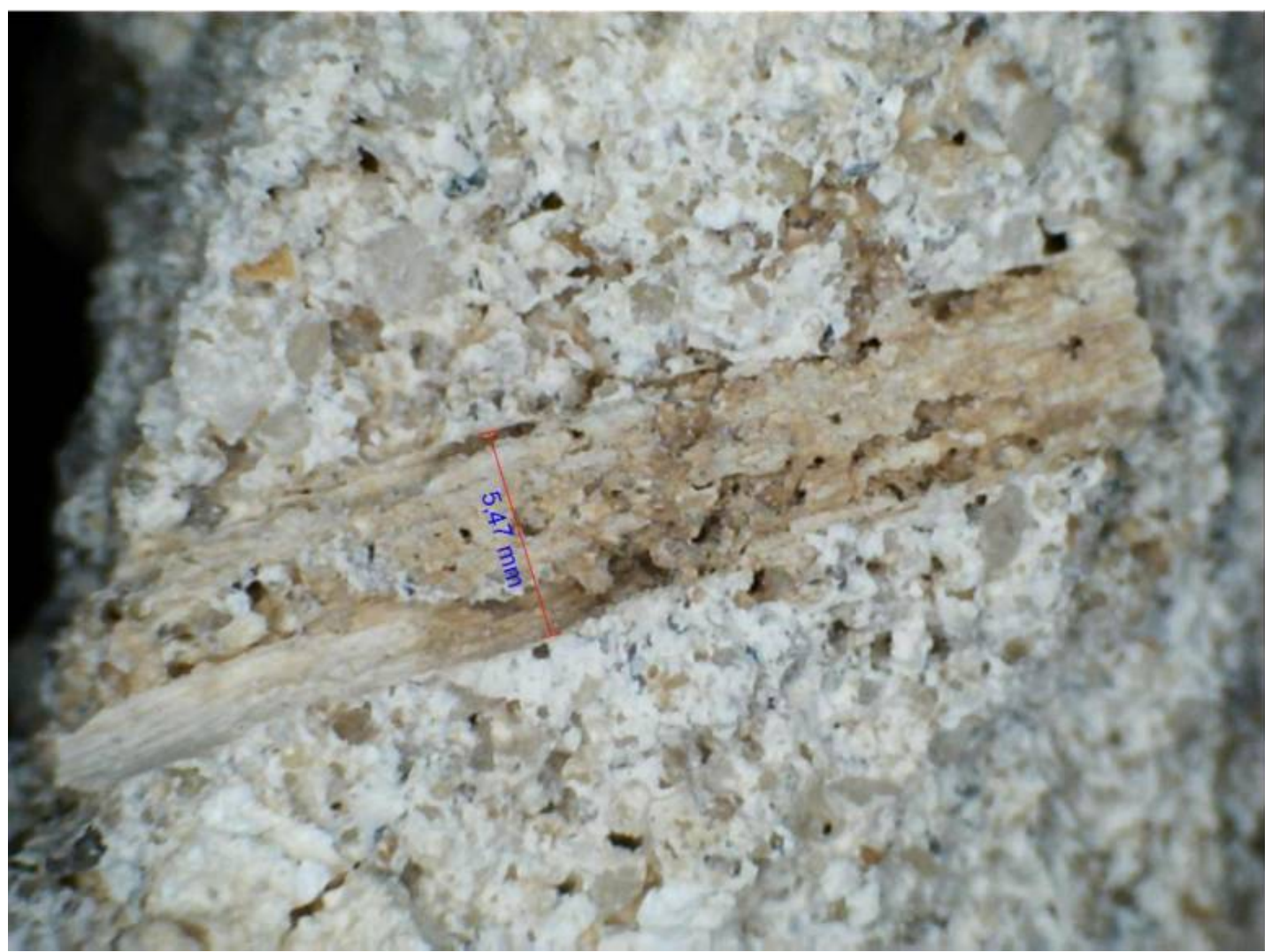

Fuente: Trébede Patrimonio y Cultura S.L.

\section{Pesajes por muestra}

Para poder realizar comparaciones con otros yacimientos y otras muestras de morteros con fragmentos de fauna, se procede a dar los resultados totales y en estimaciones de los huesos por 100 gramos de peso.

Los fragmentos de mortero recuperados de la estructura EMG1 tienen un peso total de $965 \mathrm{~g}$. Las muestras de EMG2 y EMG3 presentan unos pesos de 1186 g y 1405 g, respectivamente.

En cuanto a la relación de fragmentos de huesos por peso, los resultados son los siguientes:

(a) EMG1 (30 fragmentos) = 3,11 fragmentos $/ 100$ g;

(b) EMG2 (64 fragmentos) $=5,40$ fragmentos $/ 100$ g; $y$

(c) EMG3 (56 fragmentos) = 3,99 fragmentos/100g.

Como se puede observar, son las muestras de la estructura EMG2 las que presentan mayor número de huesos, seguida por EMG3 y EMG1, ambas con valores cercanos. De esta manera se obtiene una visión más real de la presencia de elementos óseos y dentales en morteros, al eliminar la influencia de una mayor o menor recogida de muestras.

\section{Discusiones}

La presencia de material óseo en las muestras analizadas es claramente muy superior a lo que se podría considerar como una intrusión casual de material orgánico. Hay que tener en cuenta que se han documentado 150 fragmentos de hueso de diferentes tamaños, pero en tres estructuras edificadas en tres momentos cronológicos distintos y muy distanciados entre sí, según aportan los datos del equipo de arqueólogos y otros estudios paralelos desarrollados recientemente (GUERRA GARCÍA et al., 2017; RODRÍGUEZ PASCUA et al., 2016). La memoria de la intervención se encuentra en proceso de elaboración al día de hoy. 
Figura 14 - Proceso de pesaje de las muestras en el laboratorio de Trébede, Patrimonio y Cultura S.L.

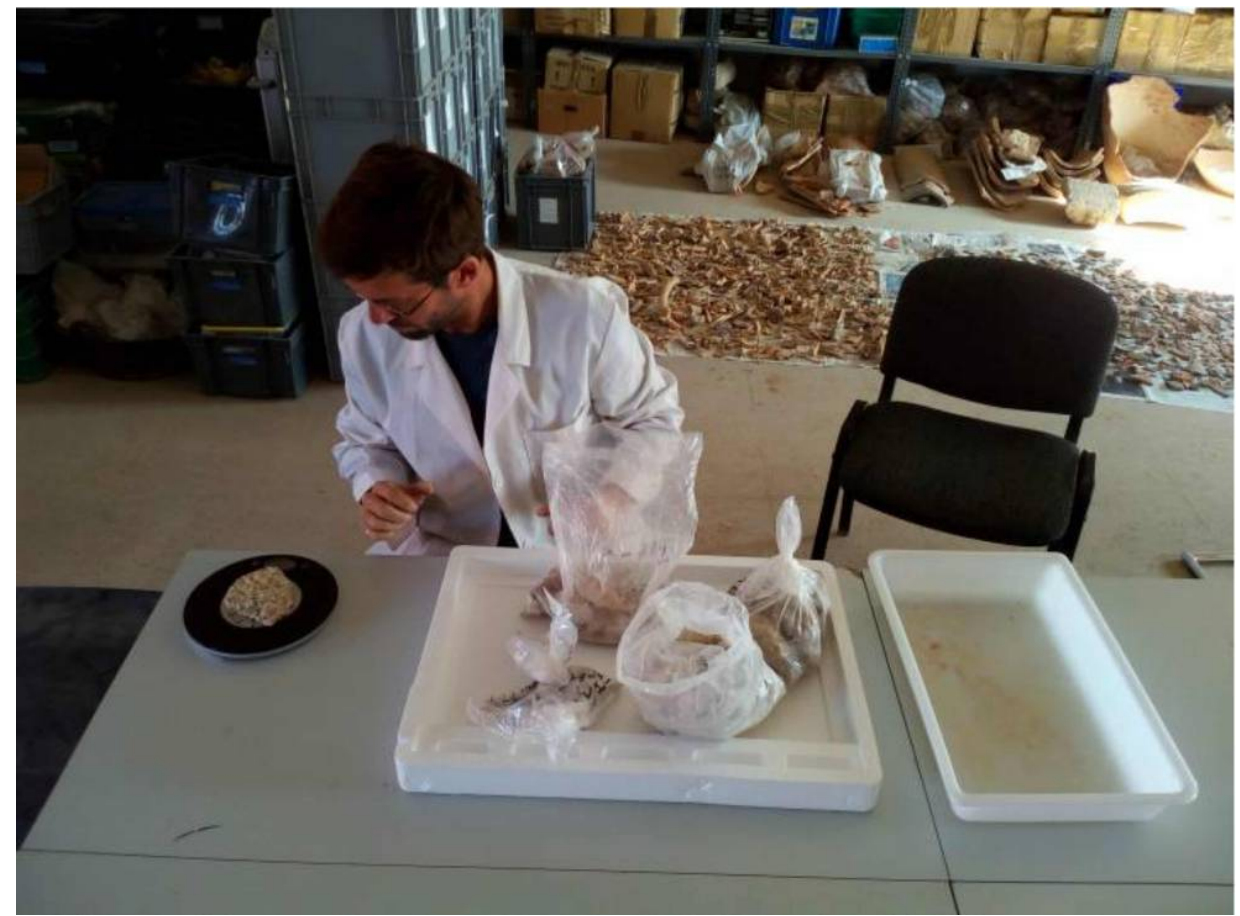

Fuente: Trébede Patrimonio y Cultura S.L.

En cualquier caso, teniendo en cuenta los datos obtenidos, habría que descartar que los fragmentos óseos actuen como un ligante natural, algo que ya se ha documentado en otros morteros:

En Turquía, en la villa neolítica de Çatal Hüyük (6.000 a. J.C.) [...] en cuanto al mortero de tierra, utilizado para la construcción de las paredes, negro y rico en cenizas y restos de huesos, todavía no disponía de un auténtico ligante [...]. (ÁLVAREZ GALINDO, 1995, p. 52).

Aparte, hay que valorar la presencia de ese material en determinadas capas y opera, como se ha podido comprobar (Figura 14). Aunque parece evidente que los artesanos o albañiles evitaban a toda costa la presencia de huesos y otros elementos orgánicos en las capas con cocciopesto- es decir, en aquellas que estaban destinadas a estar en contacto con líquidos procesados -, los mayores porcentajes de fragmentos óseos se producen precisamente en las capas de opus signinum, pero no en las de las fases que debían entrar en contacto con los líquidos, sino en las capas interiores que actuaban como agarre para las capas exteriores, más toscas y con áridos cerámicos de mayores dimensiones. Esto es muy interesante desde el punto de vista de las cualidades físico-mecánicas que adquiere el mortero, pues la inclusión de materiales orgánicos, como se explicará más adelante, podría modificar sus cualidades plásticas.
Por otro lado, los porcentajes más abundantes son los de los huesos que presentan secciones planas y redondas, siendo los menos abundantes los dentales. Eso es obvio si se tiene en cuenta que son mucho más abundantes los dos primeros grupos en la anatomía animal. Cabe destacar que actualmente, tras el estudio de los fragmentos, no es posible discernir sobre las especies de las cuales se originaron dichos huesos, aunque se está planteando una segunda fase para analizarlo.

Sí resulta más interesante el hecho de que haya ciertas diferencias entre los porcentajes obtenidos por estructura. Las muestras tomadas de la estructura EMG2 presentaron una mayor cantidad de fragmentos óseos con respecto a las restantes. Cabe destacar que esta pileta pasó por al menos una reparación casi global de su revestimiento, reparación que debió ocasionarse por un desgaste de los morteros. Esto no quiere decir que la inclusión de huesos se deba a una reparación, ya que no está comprobado que este material provea de mejores condiciones mecánicas a la mezcla. Tal y como indica Guerra García (2017), la cuestión reside en la presencia de huesos por capas y no por estructuras. Las capas interiores de las construcciones presentan aditivos orgánicos, no así las exteriores, o al menos, los presentan en menores proporciones (GUERRA GARCÍA et al., 2017). 
No se puede descartar que la incorporación de fragmentos óseos mejorase las características mecánicas de los morteros. Así, por ejemplo, Ventolá et al. (2011) comprobó que la incorporación de dosificaciones mínimas de nopal (cactácea) y mucílago (polisacárido) en los morteros alteraban la carbonatación de la mezcla, reduciendo a la mitad el tamaño medio de los poros de un mortero tras aplicar aceite de oliva, lo cual mejoraba en parte sus características plásticas. A pesar de que no son elementos habituales en morteros históricos, no cabe duda que la inclusión de aditivos orgánicos de este tipo puede mejorar las cualidades físicas de las mezclas (VENTOLÀ et al., 2011). En este sentido, Thirumalini también indica que la introducción de material orgánico mejora las condiciones mecánicas de los morteros, principalmente gracias a la adicción extra de proteínas, que mejoran, entre otras características, la plasticidad (THIRUMALINI et al., 2011).

No obstante, la presencia de material orgánico en los morteros y su análisis es, en palabras de Kuckova (2009, p. 244), “[...]un verdadero problema a la hora de interpretar su mezcla, bien como un factor casual, bien como un hecho intencionado[...]”. Tal y como indica la autora, son muchos los elementos orgánicos identificados en las caracterizaciones de los morteros de todo el mundo, desde huesos hasta azúcar, gelatina o cáscara de huevo. Sin embargo, estas adiciones tienen en común que ocasionan cambios en la reacción mecánica de los morteros, según el tipo de material y, sobre todo, según su composición química. Así, la sangre y la clara de huevo aceleran el fraguado, la leche mejora la plasticidad, la gelatina actúa como aditivo, etc. (KUCKOVA et al., 2009).

En definitiva, la incorporación de adiciones orgánicas, como puede ser el hueso, debe tenerse en cuenta como un árido más en la mezcla y no como una intrusión casual. Este fenómeno debía ser conocido por parte de los trabajadores en la época romana. Sabían perfectamente que la mezcla mejoraba si se le incorporaba un aditivo óseo y que ello repercutía positivamente en las cualidades finales del mortero. Queda por averiguar cuáles son exactamente las especies a las que corresponden los huesos encontrados.

\section{Conclusiones}

Como primera conclusión, y a la espera de poder desarrollar análisis más completos, no ha sido posible, por el momento, determinar a qué especies de animales corresponden los fragmentos encontrados dado que las piezas son de dimensiones extremadamente reducidas.
Como segunda conclusión cabe destacar la abundancia de fragmentos óseos documentados en las tres estructuras hidráulicas del complejo industrial del yacimiento. Sin embargo, dichos fragmentos no se han localizado en las capas constructivas correspondientes a los niveles hidráulicos, sino en las interiores, formando parte de las lechadas de agarre previas al revestimiento exterior (opus caementicium y opus signinum con fragmentos de ceniza).

Los fragmentos de huesos con secciones planas y redondas se observan casi por igual en las tres estructuras, lo cual indica que no se produjo ninguna selección de los huesos a la hora de realizar la mezcla con el resto de los áridos. Por el contrario, sí se aprecian diferencias con respecto a las opera, pues, como se ha indicado antes, no se han observado fragmentos óseos de ningún tipo en los revestimientos hidráulicos exteriores (opus signinum con áridos cerámicos).

Por su parte, de las capas con fragmentos óseos analizadas, los ejemplares de mayores dimensiones aparecen en el opus caementicium. De los ejemplos localizados, se destacan las impresiones dentales. Sin embargo, en la capa interior de opus signinum con aditivo ceniciento son más numerosos los huesos.

Las dimensiones de los fragmentos pueden haber influido tanto en la reacción mecánica como en la química de las mezclas y, no obstante, los oficiales romanos sabían que no se los debía incorporar en las capas exteriores, ya que podrían mermar la capacidad hidráulica del mortero. A la espera de poder realizar los análisis químicos pertinentes en las interfaces de los huesos con la cal, es innegable la intencionalidad en la inclusión de microfauna en las estructuras documentadas.

Concluyendo, tal y como indica la página editada por Pierre R. Roberge, no es de extrañar la presencia de este aditivo orgánico, pero sí es relevante en la medida que se añade según las fases constructivas:

An aggregate is material added to cement. In this report, the term does not include finely powdered additives to the cement such as ash. It is usually composed of rock fragments, chosen for their strengthening properties and occasionally for decorative reasons. Carefully chosen aggregates can make a concrete or mortar resemble natural rock. Organic material, including grasses, reeds and also bones can be used as aggregates, often in combination with rock material. Aggregates can be sub classed into categories of fine aggregates that with dimensions less than $5 \mathrm{~mm}$, and 
coarse aggregates - that with dimensions greater than 5 mm.(CORROSION..., 2016).

A pesar de los buenos resultados en cuanto al muestreo (150 fragmentos), quedan muchos análisis por realizar que nos permitan, entre otras cosas, conocer los cambios químicos y mecánicos que se producen en el interior del mortero con la incorporación de huesos o el proceso de selección de los mismos.

\section{Bibliografía}

AL-BASHAIREH, K.; HODGINS, G. W. L. AMS 14C Dating of Organic Inclusions of Plaster and Mortar From Different Structures at Petra-Jordan. Journal of Archaeological Science, v. 38, p. 485491, 2011.

ALEJANDRE SÁNCHEZ, F. J. Historia, Caracterización y Restauración de Morteros. Sevilla: Universidad de Sevilla, 2002.

ÁLVAREZ GALINDO, J.I. et al. Historia de los Morteros. Boletín Informativo del Instituto Andaluz de Patrimonio Histórico, v. 13, p. 5259, 1995.

BALBAS, A. et al. Caracterización de Morteros. In: GISBERT AGUILAR, P. (Ed.). JORNADAS DE CARACTERIZACIÓN Y RESTAURACIÓN DE MATERIALES PÉTREOS EN ARQUITECTURA, ESCULTURA Y RESTAURACIÓN, ZARAGOZA, 1., Zaragoza, 2002. Proceedings... Zaragoza, 2002.

BARONIO, G. et al. Microscopy Study of Byzantine Mortars: observation of reaction layers between lime and brick dust. In: EUROSEMINAR ON MICROSCOPY APPLIED TO BUILDING MATERIALS, 7., Delft, 1999.Proceedings... Delft, 1999.

BARTOS, P. et al. Historic MortarsCharacteristics and Test. In: INTERNATIONAL RILEM WORKSHOP, Escocia, 1999. Proceedings... Cachan: RILEM, 2000.

BINICI, H. et al. Investigation of the PhysicoChemical and Microscopic Properties of Ottoman Mortars From Erzurum (Turkey). Construction and Building Materials, v. 24, p. 1995-2002, 2010.

CORROSION DOCTORS. [Sobre]. Disponíble: $<$ http://corrosion-doctors.org/>. Acceso: 12 feb. 2016).
DE ALMEIDA, R. R. de et al. Producción Vitivinícola en el Ager de Complutum: el caso de Val de la Viña (Alovera, Guadalajara). In: NOGUERA CELDRÁN, J. M.; ANTOLINOS MARÍN, J. A. (Coords). Anales de Prehistoria y Arqueología: de vino et oleo Hispaniae, areas de producción y procesos tecnológicos del vino y el aceite en la Hispania romana, 2012.

DOEBLEY, C. E.; SPITZER, D. S. Guidelines and Standards for Testing Historic Mortars. In: KELLY, S.J. (Ed.).Standards For Preservation and Rehabilitation. Filadelfia: American Society for Testing Materials, 1996.

ELSEN, J. Microscopy of Historic Mortars: a review. In: CEMENT AND CONCRETE RESEARCH; EUROSEMINAR ON MICROSCOPY APPLIED TO BUILDING MATERIALS, 10., 2005. Proceedings... 2006.

GONZÁLEZ CORTINA, M. Recuperación de Morteros Romanos de Cal y Chamota en Aplicaciones Actuales. Madrid, 2000. Tesis Doctoral - Universidad Politécnica de Madrid. Madrid, 2000.

GOREN, Y.; GORING-MORRIS, A. N. Early Pyrotechnology in the Near East: experimental lime-plaster production at the Pre-Pottery Neolithic B site of KfarHaHoresh, Israel. Geoarchaeology, v. 23, n. 6, p. 779-798, 2008.

GUERRA GARCÍA, P. et al. Técnicas Constructivas y Estructuras Microestratigráficas en Elementos Industriales de Carácter Hidráulico Documentados en el Yacimiento Romano de La Magdalena (Alcalá de Henares, Madrid). Zona Arqueológica. Especial Vides monumenta veterum: Madrid y su entorno en época Romana, v. 20, p. 469-476, 2017.

GUERRA GARCÍA, P. Sola Romani: morteros hidráulicos romanos en la Península Ibérica. Madrid, 2015. 351 f. Tesis Doctoral - (Doctorado en Conservación y Restauración del Patrimonio Arquitectónico) - Universidad Politécnica de Madrid, Madrid, 2015.

HERAS MARTÍNEZ, C. et al. La Parcela 11796 de Alcalá de Henares: las necrópolis romana y visigoda. Primeras aportaciones. In: JORNADAS DEL PATRIMONIO ARQUEOLÓGICO EN LA COMUNIDAD DE MADRID, 6., Alcalá de Henares, 2009. Actas...Alcalá de Henares: Museo Arqueológico de la Comunidad de Madrid, 2012.

INGHAM, J. GeomaterialsUnder the Microscope. Manson: CRC Press, 2010. 
KUCKOVA, S. et al. Application of Peptide Mass Mapping on proteins in historical mortars. Journal of Cultural Heritage, v. 10, n. 2, p. 244-247, 2009.

\section{LESLIE, A. B.; EDEN, M. A Code of Practice for the Petrographic Examination of Mortars, Plasters, Renders and Related Materials. Applied Petrography Group, 2008.}

MAYS, L. et al. History of Water Cisterns: legacies and lessons. Water, v. 5, p. 1916-1940, 2013

MIDDENDORF, B. et al. Chemical-Mineralogical and Physical-Mechanical Investigations of Old Mortars. In: INTERNATIONAL RILEMWORKSHOP "HISTORIC MORTARS: CHARACTERISTICS AND TESTS”, Paisley, 1999. Proceedings... Paisley, 1999.

MIRIELLO, D. Characterisation of Archaeological Mortars From Pompeii (Campania, Italy) and Identification of Construction Phases by Compositional Data Analysis. Journal of Archaeological Science, v. 37, n. 9, p. 2207-2223, 2010.

REBOUÇAS, A. Guia Para os Alumnos da $1^{\text {a }}$ Cadeira do $1^{\circ}$ Anno de Engenharia Civil. Rio de Janeiro: Typographia Nacional, 1885.

ROBERGE, P. R. Lime Cements, Plasters, Mortars and Concretes.

Disponible:<http://corrosion-doctors.org/>.Fecha de acceso: 12 feb. 2016.
ROBINSON, J. The Oxford Companion to Wine. Oxford-Nueva York: Oxford University Press, 2006.

RODRÍGUEZ PASCUA, M. A. et al. Estructuras de Licuefacción Sísmica en el Yacimiento Romano de La Magdalena, Complutum, s. IV AD (Madrid, España). Geo Temas, v. 16, p. 1576-5172, 2016.

SICKELS, L.B. Organic Additives in Mortars. Edinburgh Architecture Research, v. 8, p. 7-20, 1981.

THIRUMALINI, P. et al. Study on the Performance Enhancement of Lime Mortar Used in Ancient Temples and Monuments in India.

Indian Journal of Science and Technology, v. 4, n. 11, p. 1484-1487, 2011.

VENTOLÀ, L. et al. Traditional Organic Additives Improve Lime Mortars: new old materials forrestoration and building natural stone fabrics. Construction and Building Materials, v. 25, p. 3313-3318, 2011.

\section{Agradecimientos}

Le agradecemos al equipo de dirección técnica y científica del yacimiento de La Magdalena - César Heras Martínez, Ana Bastida Ramírez y Virginia Galera - todas las facilidades durante la extracción de las muestras y la síntesis de los resultados. Nuestros agradecimientos también a Rui Roberto de Almeida por su ayuda en la traducción e interpretación.

\section{Pablo Guerra-García}

Universidad Politécnica de Madrid | 2 Trébede Patrimonio y Cultura S. L. | Avenida Virgen del Val, 49, 5A, Alcalá de Henares | CP 28804 | Madrid - Spain | E-mail: p.guerra.garcia@sapac.es

\section{Felipe Gómez-Moreno}

Trébede Patrimonio y Cultura S. L. | Calle Burgos, 2, Puerta 1D, Torres de la Alameda | CP 28813 | Madrid - Spain | E-mail: fgomoreno@gmail.com

\section{César Manuel Heras-Martínez}

Universidad Cumplutense de Madrid | Trébede Patrimonio y Cultura S. L. | Calle Santander, 2, 7D, Alcalá de Henares | CP 28804 | Madrid -Spain | E-mail: cmheras@gmail.com

\section{Ana Bastita-Ramírez}

Trébede Patrimonio y Cultura S. L. | Calle Santander, 2, 7D, Alcalá de Henares | CP 28804 | Madrid - Spain | E-mail: abbastida@gmail.com

Revista Ambiente Construído

Associação Nacional de Tecnologia do Ambiente Construído

Av. Osvaldo Aranha, 99 - 3o andar, Centro

Porto Alegre - RS - Brasil

CEP 90035-190

Telefone: +55 (51) 3308-4084

Fax: +55 (51) 3308-4054

www. seer. ufrgs. br/ ambienteconstruido

E-mail: ambienteconstruido@ufrgs.br 